\title{
Editorial
}

\section{TEORIA, MÉTODO E EVIDÊNCIA}

A boa articulação entre teoria, método e evidência é uma das tarefas fundamentais no planejamento de artigos científicos. O manuscrito deve ser um produto equilibrado entre observação, adequação metodológica à evidência e precisão de relato. Não é incomum observar trabalhos nos quais a transição entre método e resultados é tão imperceptível que os pesquisadores parecem ter ignorado a descrição da lógica analítica em detrimento da interpretação livre dos dados. Ou mesmo, estabelecer uma ponte entre revisão de literatura e descrição de resultados sem anunciar os preceitos envolvidos na articulação de método e evidência. Tal imprecisão não retrata o ideal da comunicação científica, uma vez que ao pesquisador cabe detalhar com a maior clareza e rigor possíveis a montagem de sua lógica argumentativa e refinamento no tratamento dos dados. Uma avaliação do manuscrito pelos parecerista passa invariavelmente por essa observação da adequação da articulação entre teoria, método e evidência.

Nessa direção, uma indicação para tornar seu manuscrito compreensível e autoevidente deve ser a descrição exaustiva dos procedimentos metodológicos. Apenas mencionar o tipo de análise dos dados (ex. análise de conteúdo) não é o suficiente para identificar os procedimentos utilizados na mediação entre teoria de base, evidência e interpretação. O leitor fica às escuras sobre como os procedimentos foram de fato conduzidos, o que diminui a confiabilidade da pesquisa e a possibilidade de replicação do estudo. Uma alternativa adicional na descrição do método é a utilização de organogramas ou ilustrações que facilitem a compreensão dos instrumentos e procedimentos de análise (Oliveira, 2014).

Relatar resultados também não pode ser entendido como uma tarefa de desinfecção de possíveis erros ou problemas ocorridos no decorrer da coleta dos dados. Isto é, relatar eventuais problemas nos procedimentos indica idoneidade metodológica e ainda representa a realidade da pesquisa empírica, de que em geral não se acerta sem antes errar. Deve ser incentivado, por exemplo, a descrição da exclusão de participantes por eventuais problemas nos registros de dados ou por não preenchimento de critérios na seleção da amostra. Assim como mencionar estudos pilotos e ensaios estatísticos realizados para calcular o poder de estimativa dos resultados.

Em especial, nesse tocante, cabe mencionar o atual e intenso debate na comunidade internacional sobre os problemas gerados pela busca incessante de significância estatística que confirme hipóteses de pesquisa $(p<0,05)$. Esta prática tem recebido o nome de $P$-Hacking e envolve a tentativa de múltiplas manipulações estatísticas até se encontrar o resultado desejado (Nuzzo, 2014). O que ocorre é que tradicionalmente não se relatam esses ensaios e muito menos os estudos que não "funcionaram" (publication bias). Simonsohn, Nelson e Simmons (2014) estimam que dependendo da escolha estatística pode-se produzir uma taxa de até $60 \%$ de falsos-positivos em um único estudo. Ou seja, em busca da melhor solução para a produção de estudos que "funcionam" comete-se uma estimativa inadequada sobre o poder dos resultados para a confirmação de hipóteses. Daí a necessidade da criação de uma cultura sobre o relato dos ensaios estatísticos, de modo a tornar o processo científico claro e verificável.

Do mesmo modo, em estudos que se utilizam de análise qualitativa, deve-se empregar rigor na explicitação do método, estruturando visivelmente a relação entre teoria, opção metodológica e interpretação dos dados. Descrever as variações interpretativas ou os impasses metodológicos na análise dos dados pode auxiliar no fortalecimento da discussão do estudo. Relatar trechos de entrevista, por exemplo, deve ter finalidade adicional de ilustração dos procedimentos de análise e não apenas de enunciação da interpretação teórica dos autores. Nesse sentido, pensa-se a escrita 
de artigos científicos como uma divulgação de resultados aliada ao ensino do processo lógico vinculado ao fazer científico. Defende-se que o leitor deve ter a oportunidade de acompanhar com clareza o arrazoado argumentativo estabelecido pelos pesquisadores na integração entre teoria, método e evidência.

Thiago Gomes de Castro Pós-graduação em Psicologia PUCRS

\section{REFERÊNCIAS}

Nuzzo, R. (2014). Scientific method: statistical errors. Nature, 506(7487), 150-152.

Oliveira, M. Z. (2014). Como escrever um artigo empírico. In S. H. Koller, M. C. P. P. Couto, \& J. V. Hohendorff(Orgs.). Manual de Produção Científica (pp. 71-89). Porto Alegre: Penso Editora.

Simonsohn, U., Nelson, L. D., \& Simmons, J. P. (2014). P-Curve: a key to the file-drawer. Journal of Experimental Psychology: General, 143(2), 534-547. 